\title{
AMENDMENTS
}

\section{Publisher Correction: Multi-omic analysis of selectively vulnerable motor neuron subtypes implicates altered lipid metabolism in ALS}

Hojae Lee, Jae Jin Lee (D), Na Young Park, Sandeep Kumar Dubey D, Taeyong Kim (D), Kai Ruan, Su Bin Lim (D), Seong-Hyun Park, Shinwon Ha, Irina Kovlyagina, Kyung-tai Kim, Seongjun Kim (D, Yohan Oh (D), Hyesoo Kim, Sung-Ung Kang (D), Mi-Ryoung Song, Thomas E. Lloyd (D), Nicholas J. Maragakis (D), Young Bin Hong (D), Hyungjin Eoh (D) and Gabsang Lee (iD

Correction to: Nature Neuroscience https://doi.org/10.1038/s41593-021-00944-z, published online 15 November 2021.

In the version of this article originally published, there were errors in Fig. 1i-k. The $x$-axis labels now reading "FL1 (HB9::GFP) $\rightarrow$ " initially appeared as "FL1 (PHOX2B::GFP) $\rightarrow$." The changes have been made to the online version of the article.

Published online: 21 December 2021

https://doi.org/10.1038/s41593-021-01000-6

(c) The Author(s), under exclusive licence to Springer Nature America, Inc. 2021

\section{Publisher Correction: Ventral striatal islands of Calleja neurons control grooming in mice}

Yun-Feng Zhang, Luigim Vargas Cifuentes, Katherine N. Wright iD, Janardhan P. Bhattarai, Julia Mohrhardt, David Fleck (D), Emma Janke, Chunjie Jiang (D), Suna L. Cranfill, Nitsan Goldstein, Mary Schreck, Andrew H. Moberly, Yiqun Yu, Benjamin R. Arenkiel D, J. Nicholas Betley (D), Wenqin Luo, Johannes Stegmaier, Daniel W. Wesson (D), Marc Spehr (iD, Marc V. Fuccillo (iD and Minghong Ma (D)

Correction to: Nature Neuroscience https://doi.org/10.1038/s41593-021-00952-z, published online 18 November 2021.

In the version of this article initially published, a technical error led to the omission of Christiane Schreiweis from the Reviewer Recognition statement. The Peer Review Information section has now been updated in the HTML and PDF versions of the article to reflect her contributions.

Published online: 6 January 2022

https://doi.org/10.1038/s41593-021-01003-3

(c) The Author(s), under exclusive licence to Springer Nature America, Inc. 2022 